\title{
Efeito da anti-sepsia da ferida cirúrgica alveolar sobre o crescimento bacteriano em fios de sutura de algodão ${ }^{\dagger}$
}

\section{Effect of the antisepsis of the alveolar surgical wound on bacterial growth over cotton suture threads}

\author{
Ulysses Nicida SOARES* \\ Izabel Yoko ITO** \\ Valdemar Mallet da ROCHA BARROS***
}

\begin{abstract}
SOARES, U. N.; ITO, I. Y.; ROCHA BARROS, V. M. da. Efeito da anti-sepsia da ferida cirúrgica alveolar sobre o crescimento bacteriano em fios de sutura de algodão. Pesqui Odontol Bras, v. 15, n. 1, p. 41-46, jan./mar. 2001.

Embora os fios de sutura empregados rotineiramente em cirurgias bucais possam favorecer o acúmulo e o crescimento bacteriano, há poucos trabalhos na literatura relatando preocupação com a anti-sepsia da ferida cirúrgica durante o período pós-operatório e antes de sua remoção. O presente trabalho teve por objetivo avaliar o efeito de dois métodos de anti-sepsia intra-oral sobre o crescimento bacteriano em fios de sutura de algodão. Os resultados evidenciaram que todos os fios de sutura apresentaram-se contaminados com estreptococos, antes e após a anti-sepsia da ferida cirúrgica. A análise dos resultados obtidos permitiu concluir que os dois métodos de anti-sepsia avaliados reduziram o número de estreptococos isolados dos fragmentos de fios de sutura, entretanto, a análise estatística demonstrou que os dois métodos avaliados não apresentaram diferenças estatisticamente significantes.
\end{abstract}

UNITERMOS: Anti-sepsia; Cetilpiridínio; Clorexidina; Cirurgia bucal.

\section{INTRODUÇÃO}

A contaminação da ferida cirúrgica e dos fios de sutura representou durante muito tempo uma ameaça ao sucesso das intervenções cirúrgicas. A passagem de microrganismos da microbiota oral para o interior da ferida cirúrgica estará favorecida ou prejudicada em função das propriedades de absorção de alguns tipos de fios de sutura ${ }^{10,11}$, dos cuidados de higienização oral durante o pós-operatório e da técnica empregada na remoção da sutura.

Os fios de sutura de algodão e os de seda são os mais freqüentemente utilizados em cirurgia dento-alveolar, para suturas intra-orais. $\mathrm{O}$ fio de algodão, por ser multifilamentar, constituído de celulose com alto grau de absorção, facilita o acúmulo de fluidos, os quais constituem um meio propício ao desenvolvimento microbiano. LILLY ${ }^{11}$ (1968) salientou as propriedades absorventes do fio de sutura de algodão, que podem facilitar a penetração de microrganismos no interior da ferida cirúrgica através da sutura e produzir reações inflamatórias locais.

LIEDKE et al. ${ }^{10}$ (1975), avaliando os fios de algodão, seda, linho, poliéster, "catgut" e "nylon", empregados em feridas de extração dental, constataram que o algodão foi aquele que apresentou maior número de colônias bacterianas e que a intensidade da contaminação interferia na cicatrização dos tecidos.

SALOMÃO et $a l .{ }^{14}$ (1982) avaliaram o efeito da anti-sepsia intra-oral, empregando o cloreto de cetilpiridinnio associado ao peróxido de hidrogênio, sobre o crescimento bacteriano no fio de sutura de algodão. O método avaliado consistia de duas atomizações da cavidade bucal com $35,0 \mathrm{ml}$ de cloreto de cetilpiridínio a $50,0 \%$, intercalados por limpeza das faces dentais com cotonetes embebidos em peróxido de hidrogênio a 3,0\%. Os resultados obtidos evidenciaram que a anti-sepsia da cavidade oral, realizada previamente à retirada da sutura, redu-

$\dagger$ Dissertação de Mestrado apresentada à Faculdade de Odontologia de Ribeirão Preto da USP.

* Mestre em Odontologia, Área de Reabilitação Oral, Faculdade de Odontologia de Ribeirão Preto da USP.

** Professora Titular do Departamento de Ciências da Saúde, Faculdade de Ciências Farmacêuticas de Ribeirão Preto da USP.

*** Professor Associado do Departamento de Cirurgia e Traumatologia Buco-Maxilo-Facial, Faculdade de Odontologia de Ribeirão Preto da USP. 
SOARES, U. N.; ITO, I. Y.; ROCHA BARROS, V. M. da. Efeito da anti-sepsia da ferida cirúrgica alveolar sobre o crescimento bacteriano em fios de sutura de algodão. Pesqui Odontol Bras, v. 15, n. 1, p. 41-46, jan./mar. 2001.

ziu em até $77,1 \%$ o número de microrganismos encontrados nos fios de sutura.

Além do cloreto de cetilpiridínio, diversos outros anti-sépticos têm sido empregados em Cirurgia Bucal e em Periodontia, entre os quais destaca-se a clorexidina. SIMMONS et al. ${ }^{15}$ (1990) relataram que a aplicação de clorexidina a $0,2 \%$ na margem gengival, antes do tratamento odontológico, reduz a severidade da bacteriemia após tratamento, podendo ser empregada em pacientes de risco para endocardite como complemento da antibioticoterapia.

GAYOTTO et al. ${ }^{7}$ (1987), avaliando a freqüência de bacteriemia após a remoção de sutura, constataram hemoculturas positivas em nove $(50,0 \%)$ casos estudados. Os resultados evidenciaram microrganismos anaeróbios facultativos como Streptococcus, Staphylococcus aureus e Lactobacillus, e anaeróbios estritos como Veillonella, Bifidobacterium, Peptococcus, Bacteroides, Peptostreptococcus e Fusobacterium. KING et al. ${ }^{9}$ (1988), estudando a incidência de bacteriemia após a remoção de suturas intra-orais em 20 pacientes submetidos à extração dental, obtiveram hemocultura positiva em um caso $(5,0 \%)$. O microrganismo isolado foi o Peptostreptococcus intermedius, uma espécie anaeróbia de estreptococos, sugerindo a origem bucal.

GIGLIO et $a l .{ }^{8}$ (1992), avaliando a incidência de bacteriemia após a remoção de suturas intraorais, obtiveram hemoculturas positivas de Streptococcus sanguis, Streptococcus millieri, Streptococcus mitis e Bacillus $s p$. em quatro $(16,0 \%)$ dos 25 casos estudados. Ao avaliarem a incidência de bacteriemia provocada por microrganismos anaeróbios, obtiveram hemocultura positiva em um $(6,0 \%)$ dos 17 pacientes e o microrganismo isolado foi o Peptostreptococcus. Esses autores observaram uma correlação positiva entre o número de suturas removidas e a incidência de bacteriemia. Todas as hemoculturas positivas ocorreram em pacientes que tiveram cinco ou mais suturas removidas. Entretanto, não observaram qualquer relação entre bacteriemia e evidência clínica de sangramento no momento de remoção da sutura. Esses achados revestem-se de importância, uma vez que há relação entre bacteriemia de origem dental e endocardite infecciosa, conforme demonstrado por diversos autores ${ }^{2,3,16}$.

KING et al. ${ }^{9}$ (1988), apesar de não terem indicado a necessidade de profilaxia antibiótica previamente à remoção de sutura em pacientes cardía$\cos$ de alto risco, sugeriram tal procedimento à consideração, para pacientes de maior risco, como os portadores de implantes de válvulas cardiacas ou aqueles com história anterior positiva de endocardite infecciosa. GIGLIO et $a .^{8}$ (1992) compartilham dessa opinião e consideram como candidatos à profilaxia antibiótica os pacientes de alto risco, com múltiplas suturas para serem removidas. Apesar da importância da sutura na prevenção ou no desenvolvimento de perturbações da ferida cirúrgica, constata-se que há poucos trabalhos avaliando bacteriologicamente a ação de anti-sépticos na redução da contaminação dos fios de sutura empregados na cavidade oral. Assim, este trabalho tem por objetivo avaliar bacteriologicamente os efeitos da anti-sepsia da ferida cirúrgica alveolar humana sobre o crescimento bacteriano em suturas intra-orais, utilizando fios de sutura de algodão.

\section{MATERIAL E MÉTODO}

Foram selecionados 20 pacientes da clínica de Cirurgia da Faculdade de Odontologia de Ribeirão Preto - USP, com idade entre 17 e 20 anos e com indicação de extração de terceiros molares inferiores inclusos, sem qualquer processo patológico ou infeccioso constatado clínica ou radiograficamente. Os pacientes apresentavam boas condições de saúde, higiene oral satisfatória e não estavam sob terapêutica medicamentosa ou usando qualquer tipo de anti-séptico bucal. Dois dias antes da intervenção cirúrgica, com os exames clínico e radiográfico concluídos, todos os pacientes foram submetidos a uma profilaxia dental com pedra-pomes e taça de borracha, e receberam orientação no sentido de não tomarem nenhuma medicação e nem usarem anti-sépticos bucais no período pré-operatório.

As vinte extrações dos terceiros molares inferiores foram planejadas pelo operador, que padronizou a técnica cirúrgica a ser empregada. A sutura foi realizada com fio de algodão 2-0 (Ethicon Johnson \& Johnson), com dois pontos interrompidos na incisão vestibular e outros dois na incisão sobre o trígono retromolar.

Os vinte casos selecionados foram alocados em dois grupos de dez, denominados grupo Cepacol (C - Cepacol - Merrel Lepetit Farmacêutica Ltda.) e grupo Periogard ( $\mathrm{P}$ - Periogard - Colgate Palmolive Ltda.) e todos os pacientes receberam instruções para iniciarem a anti-sepsia da ferida cirúrgica 24 horas após o término da cirurgia. Nos dois grupos, após a escovação dos dentes nas áreas não operadas, os pacientes do grupo $\mathrm{C}$ fizeram bochechos, por um minuto, com 15,0 $\mathrm{ml}$ de Cepacol a $50,0 \%$ após o café da manhã, o almoço e o jantar, 
SOARES, U. N.; ITO, I. Y.; ROCHA BARROS, V. M. da. Efeito da anti-sepsia da ferida cirúrgica alveolar sobre o crescimento bacteriano em fios de sutura de algodão. Pesqui Odontol Bras, v. 15, n. 1, p. 41-46, jan./mar. 2001.

assim como antes do descanso noturno. Os pacientes do grupo $\mathrm{P}$, fizeram um único bochecho com $15,0 \mathrm{ml}$ de Periogard $(0,12 \%)$, por um minuto, após o café da manhã.

As suturas foram mantidas por cinco dias, quando foram removidas pela técnica preconizada por ATTERBURY; VAZIRANI ${ }^{1}$ (1961). Para os testes microbiológicos, em ambos os grupos, foram empregados os fios das duas suturas localizadas sobre o trígono retromolar. Um dos pontos era removido previamente à anti-sepsia da ferida cirúrgica e o outro após a mesma. No grupo Cepacol, a anti-sepsia empregada previamente à remoção da sutura constou de dois bochechos com 15,0 ml de Cepacol durante um minuto, intercalados pela limpeza das faces dentais e da ferida cirúrgica com gaze esterilizada embebida em peróxido de hidrogênio a 3,0\%. Para o grupo Periogard, a anti-sepsia foi realizada apenas com um bochecho de 15,0 ml de Periogard, durante um minuto. Após a remoção da sutura, foram obtidas duas amostras de 2,0 $\mathrm{mm}$ de fio de cada uma das suturas, sendo uma da porção externa (bucal) da ferida cirúrgica, e outra da porção interna (alveolar), ambas introduzidas, assepticamente, em tubos de ensaio contendo $1,0 \mathrm{ml}$ de solução salina tamponada fosfatada com Tween 80 (PBST), que foram encami- nhadas ao Laboratório de Microbiologia da Faculdade de Ciências Farmacêuticas de Ribeirão Preto da USP, para processamento microbiológico.

Visando à contagem e à identificação dos microrganismos, o material obtido era submetido a diluição decimal e semeado nos meios de cultura ágar Mitis salivarius (Ms), ágar sacarose bacitracina $\left(\mathrm{SB}_{20}\right)$, ágar gema de ovo (Ni), ágar MacConkey (MC). As placas Ms empregadas para a determinação de unidades formadoras de colônias e as de $\mathrm{SB}_{20}$ para estreptococos do grupo mutans foram incubadas em microaerofilia durante 48 a 72 horas. No entanto, as placas de Ni para Staphylococcus aureus e MC para bacilos gram-negativos foram incubadas a $37^{\circ} \mathrm{C}$ durante 24 a 48 horas conforme Figura 1.

\section{Análise estatística}

Os dados obtidos foram analisados comparativamente utilizando o teste Wilcoxon.

\section{RESULTADOS}

Todos os fios de sutura mostraram-se contaminados, antes e após a realização da anti-sepsia, tanto pelo lado bucal como pelo alveolar. Os fios de sutura do lado bucal, dos pacientes que fizeram

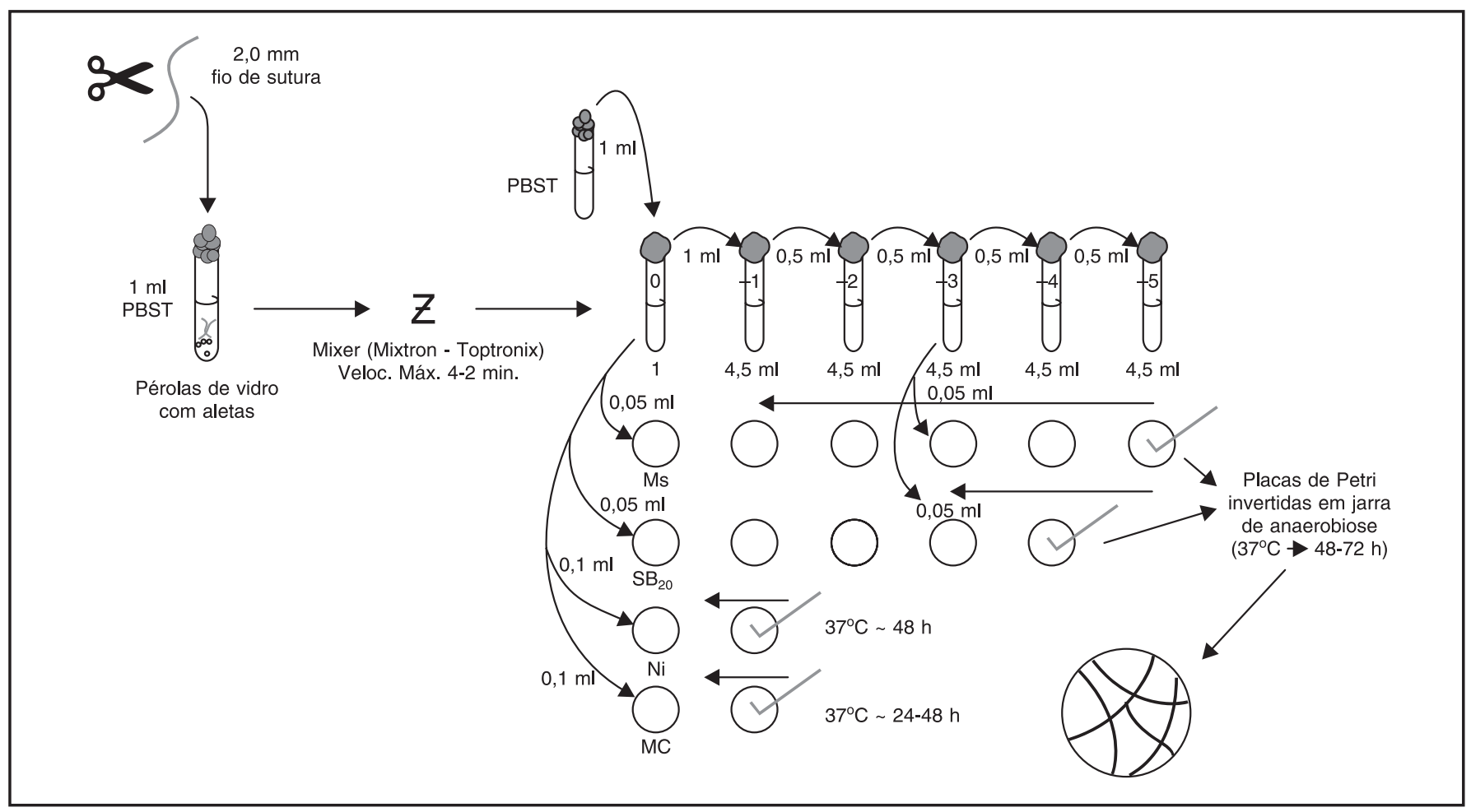

FIGURA 1 - Esquema de colheita, semeadura e identificação dos microrganismos. PBST - solução salina tamponada fosfatada; Ms - ágar Mitis salivarius; $\mathrm{SB}_{20}$ - ágar sacarose bacitracina; Ni - ágar gema de ovo; MC - ágar MacConkey. 
SOARES, U. N.; ITO, I. Y.; ROCHA BARROS, V. M. da. Efeito da anti-sepsia da ferida cirúrgica alveolar sobre o crescimento bacteriano em fios de sutura de algodão. Pesqui Odontol Bras, v. 15, n. 1, p. 41-46, jan./mar. 2001.

anti-sepsia com Cepacol durante o pós-operatório, apresentaram-se, na maior parte dos casos, mais contaminados do que aqueles submetidos à antisepsia com o Periogard. Do lado alveolar dos fios de sutura, o desempenho das duas soluções foi praticamente o mesmo, uma vez que, em cinco casos, a maior contaminação ocorreu nos pacientes que utilizaram o Periogard e, em quatro, naqueles que empregaram o Cepacol (Gráfico 1).

A análise estatística comparativa dos resultados obtidos revelou que as diferenças observadas no número de estreptococos, antes e após a antisepsia por um dos dois métodos avaliados, não foram estatisticamente significantes, demonstrando que os dois tratamentos apresentam, sob o ponto de vista estatístico, a mesma eficácia.

Os estreptococos foram os microrganismos mais freqüentemente isolados. Destes, foram identificadas as espécies Streptococcus mutans e Streptococcus sobrinus. Além desses, foram isolados Staphylococcus aureus e bacilos gram-negativos.

Os logaritmos do número de estreptococos encontrados nos fragmentos de fios de sutura dos lados bucal e alveolar, antes e após a anti-sepsia, podem ser evidenciados na Tabela 1 .

A análise estatística dos resultados obtidos demonstrou que a redução do número de estreptococos, após a realização da anti-sepsia no lado alveolar dos fios de sutura submetidos à ação do Cepacol, foi significante ao nível de 5,0\%. Nos demais fragmentos dos fios de sutura do lado bucal tratados com Cepacol e nos fragmentos bucais e alveolares do grupo tratado com Periogard, essa redução foi significante ao nivel de 1,0\%. Somente em dois casos do grupo $\mathrm{C}$, os fios de sutura do lado bucal apresentaram contaminação com Staphylococcus aureus, previamente à anti-sepsia quando

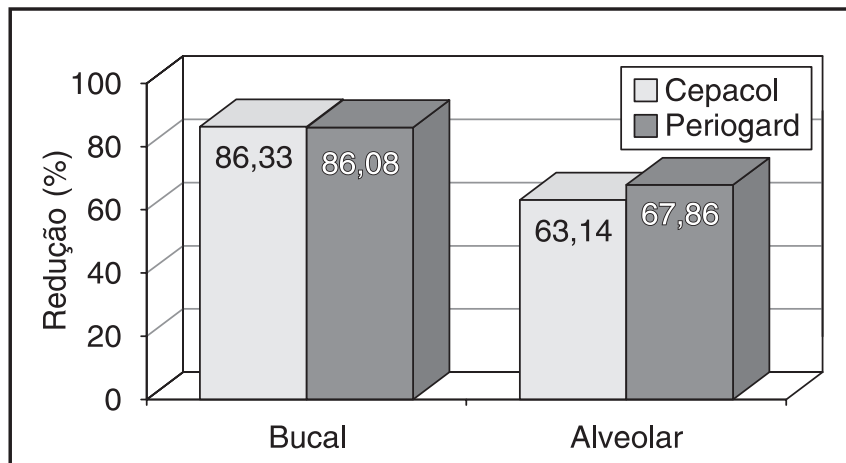

GRÁFICO 1 - Representação gráfica da redução percentual do número de estreptococos de fragmentos de fios de sutura de algodão do lado bucal e alveolar da ferida cirúrgica após a anti-sepsia. da retirada da sutura. A anti-sepsia nesses casos eliminou os Staphylococcus aureus.

\section{DISCUSSÃO}

Os resultados apresentados demonstram que os dois métodos de anti-sepsia avaliados mostraram-se eficazes na redução dos microrganismos. Eles confirmam a afirmação de SALOMÃO et al. ${ }^{14}$ (1982) de que o fio de sutura de algodão é capaz de servir de veículo de condução de material séptico do meio bucal para o interior da ferida cirúrgica, pois todas as amostras avaliadas no presente trabalho mostraram-se contaminadas antes da remoção da sutura.

Todos os microrganismos isolados, a partir dos fragmentos de fios de sutura, podem ser encontrados no sulco gengival, na placa dental ou na saliva, o que reforça a necessidade do emprego de antisepsia intra-oral pré-operatória, bem como da ferida cirúrgica durante o pós-operatório e também quando da retirada da sutura.

Os fios de sutura do lado bucal da ferida cirúrgica dos pacientes que foram submetidos, no pós-operatório, à anti-sepsia com Cepacol quatro vezes ao dia apresentaram-se antes da anti-sepsia da ferida cirúrgica, na maior parte dos casos, mais contaminados com estreptococos do que aqueles submetidos à anti-sepsia com o Periogard, o que sugere maior eficácia desse último.

Do lado alveolar, os índices de contaminação dos fios de sutura antes da anti-sepsia da ferida cirúrgica foram similares e o desempenho dos dois métodos, durante o período pós-operatório, foi praticamente o mesmo, uma vez que, em cinco casos, a maior contaminação ocorreu com pacientes submetidos à anti-sepsia com Periogard e em quatro deles com o Cepacol. No caso restante, o índice de contaminação foi igual.

A ação do Periogard, empregado durante o período pós-operatório, sugere uma ação residual, a qual encontra respaldo científico. A clorexidina

TABELA 1 - Logaritmos do número total de estreptococos encontrados por milímetro de fio de sutura de algodão, dos lados bucal e alveolar dos 20 casos, antes e após a anti-sepsia da ferida cirúrgica.

\begin{tabular}{l|c|c|c|c}
\hline \multirow{2}{*}{ Lado } & \multicolumn{2}{|c|}{ Bucal } & \multicolumn{2}{c}{ Alveolar } \\
\cline { 2 - 5 } Produto & Antes & Depois & Antes & Depois \\
\hline Cepacol & 69,112 & $59,429^{* *}$ & 58,408 & $55,126^{*}$ \\
\hline Periogard & 63,131 & $54,837^{* *}$ & 61,047 & $55,489^{* *}$ \\
\hline \hline
\end{tabular}

* Significante ao nivel de 5,0\%; ** significante ao nivel de $1,0 \%$. 
SOARES, U. N.; ITO, I. Y.; ROCHA BARROS, V. M. da. Efeito da anti-sepsia da ferida cirúrgica alveolar sobre o crescimento bacteriano em fios de sutura de algodão. Pesqui Odontol Bras, v. 15, n. 1, p. 41-46, jan./mar. 2001.

liga-se às superficies aniônicas da cavidade oral, sendo gradualmente liberada, promovendo assim uma liberação contínua e ação antimicrobiana. FEIST et $a .^{5}$ (1989) relataram que a clorexidina pode ficar retida tanto na superficie dental como na mucosa bucal, tendo o seu efeito proporcional à capacidade de adsorção por essas estruturas, de onde é liberada para a cavidade oral, mantendo-se atuante, em média, por 24 horas. Ela tem grande afinidade pela parede celular de microrganismos, provavelmente, devido a uma interação entre a positividade de sua molécula e a carga negativa da parede celular de microrganismos. Essa afinidade induz mudanças nas estruturas da superfície da parede celular, produzindo a perda do equilíbrio osmótico e a precipitação do citoplasma. Ocorre um aumento da permeabilidade da parede celular bacteriana, permitindo a saída de conteúdo citoplasmático, provocando a sua morte. $\mathrm{O}$ fato de a eficiência da clorexidina não ser afetada pela presença de matéria orgânica, incluindo sangue e pus, parece contribuir positivamente para a sua ação ${ }^{12}$.

Há que se considerar, entretanto, que os indices percentuais de redução do número total de estreptococos, do lado bucal do fio de sutura, previamente à realização da anti-sepsia da ferida cirúrgica para a retirada da sutura, empregando qualquer um dos dois métodos avaliados, foram muito próximos. No lado alveolar do fragmento de fio de sutura, a redução observada foi menor, provavelmente devido à dificuldade do fio ser atingido pelo anti-séptico. A melhor atuação do Periogard, verificada no fragmento de fio de sutura do lado alveolar, é dificil de ser explicada. Provavelmente, o fio de sutura do lado alveolar, menos sujeito ao constante fluxo salivar, mantém por mais tempo o Periogard retido no fio, favorecendo dessa forma a sua ação anti-séptica por um tempo maior do que aquele observado no lado bucal. Um fator que pode ter interferido na ação do Cepacol no lado alveolar do fio de sutura pode ter sido a presença de matéria orgânica aderida ao fio de sutura e a falta de ação residual prolongada. Conforme afirmam FROSTELL ${ }^{6}$ (1956) e ESPLIN ${ }^{4}$ (1967), a atividade antimicrobiana de compostos quaternários de amônio como o cloreto de cetilpiridínio pode ser reduzida pela presença de matéria orgânica.

Considerando-se apenas o número total de estreptococos, verifica-se que o método de anti-sepsia que emprega o bochecho com Cepacol associado ao peróxido de hidrogênio promoveu uma redução ligeiramente maior no número de estreptococos encontrados no lado bucal dos fios de sutura do que aquela relatada por SALOMÃO et $a l .{ }^{14}$, em 1982. Esses autores observaram uma redução de $82,67 \%$ no número de estreptococos do lado bucal dos fios de sutura. No entanto, a redução observada por SALOMÃO et al. ${ }^{14}$ (1982) do lado alveolar do fio de sutura $(90,74 \%)$ foi muito superior à obtida neste trabalho. Essa diferença nos resultados obtidos nos dois trabalhos no lado alveolar do fio de sutura talvez possa ser explicada pela utilização de atomizador por SALOMÃO et al. ${ }^{14}$ (1982), o qual, projetando a solução anti-séptica sob pressão sobre o fio de sutura, promove uma limpeza mecânica mais efetiva do que quando se emprega o bochecho, ao mesmo tempo em que promove uma desinfecção química.

As reduções nos números de microrganismos observados após a anti-sepsia da ferida cirúrgica refletem a ação imediata das soluções empregadas. Os resultados obtidos por ROCHA BARROS ${ }^{13}$ (1996), ao avaliar a redução do número de estreptococos do sulco gengival, empregando os mesmos métodos de anti-sepsia intra-oral utilizados no presente trabalho, sugerem que se a sutura fosse retirada 15 minutos após a anti-sepsia da ferida cirúrgica ter sido realizada, provavelmente, os indices de redução microbiana seriam maiores. $\mathrm{O}$ contato íntimo do anti-séptico com o fio de sutura saturado com anti-séptico parece favorecer a sua ação antimicrobiana.

Em vista dos trabalhos citados, verifica-se a necessidade de se instituir na prática cirúrgica rotinas que visem eliminar ou diminuir a possibilidade de contaminação do fio de sutura, bem como da ferida cirúrgica. A inobservância dessas rotinas durante o período pós-operatório e quando da retirada da sutura pode resultar em processo infeccioso e/ou retardo no processo de reparo ou cicatrização da ferida cirúrgica, ou ainda em bacteriemia transitória, com graus variados de repercussão sistêmica.

Deve ser destacado que o bochecho com as soluções avaliadas, ao reduzir o número de bactérias da cavidade oral, em especial do sulco gengival e da placa dental previamente à uma extração dental, pode diminuir a freqüência de bacteriemia pós-exodontia. A anti-sepsia promove a redução do inóculo e do número de diferentes espécies de microrganismos que poderão entrar na corrente circulatória; menor número de microrganismos entrando na corrente circulatória significa maior 
SOARES, U. N.; ITO, I. Y.; ROCHA BARROS, V. M. da. Efeito da anti-sepsia da ferida cirúrgica alveolar sobre o crescimento bacteriano em fios de sutura de algodão. Pesqui Odontol Bras, v. 15, n. 1, p. 41-46, jan./mar. 2001.

rapidez na sua eliminação pelos mecanismos de defesa orgânica. A redução da contaminação do fio de sutura é também importante, pois a presença de microrganismos em fios de sutura na cavidade bucal é, provavelmente, a causa de reações inflamatórias, que podem comprometer o processo de cicatrização ou de reparo alveolar.

\section{CONCLUSÕES}

A análise dos resultados obtidos permite concluir que os dois métodos de anti-sepsia da ferida cirúrgica avaliados reduziram o número de estreptococos dos fragmentos dos fios de sutura, mas as diferenças observadas não se apresentaram estatisticamente significantes.

SOARES, U. N.; ITO, I. Y.; ROCHA BARROS, V. M. da. Effect of the antisepsis of the alveolar surgical wound on bacterial growth over cotton suture threads. Pesqui Odontol Bras, v. 15, n. 1, p. 41-46, jan./mar. 2001.

The objective of this study was to evaluate bacterial growth on cotton suture. The efficiency of cetylpyridinium chloride $(50 \%)$, hydrogen peroxide $(3 \%)$ and chlorhexidine $(0.12 \%)$ in antisepsis was investigated. For that, 20 patients who were submitted to extraction of impacted lower third molars were studied. Five days after extraction, samples were obtained from the oral and alveolar sides of the sutures, before and after antisepsis of the wounds, and were submitted to bacteriological analysis. Bacterial growth was observed in all examined samples. The number of streptococci decreased after antisepsis and there were no statistically significant differences between the methods of antisepsis used.

UNITERMS: Antisepsis; Cetylpyridinium; Chlorhexidine; Surgery, oral.

\section{REFERÊNCIAS BIBLIOGRÁFICAS}

1. ATTERBURY, R. A.; VAZIRANI, S. J. Removal of sutures following oral surgery. Oral Surg Oral Med Oral Pathol, v. 14, n. 6, p. 658-661, June 1961.

2. BAYLISS, R.; CLARKE, C.; OAKLEY, C. M. et al. The microbiology and pathogenesis of infective endocarditis. $\mathbf{B r}$ Heart J, v. 50, n. 6, p. 513-519, 1983.

3. DURACK, D. Prevention of infective endocarditis. New England J Med, v. 332, n. 1, p. 38-43, Jan. 1995.

4. ESPLIN, D. W. Anti-sépticos e desinfetantes; fungicidas ectoparasiticidas. In: GOODMAN, L. S.; GILMAN, A. As bases farmacológicas da terapêutica. 3. ed., Rio de Janeiro : Guanabara Koogan, 1967. p. 928-961.

5. FEIST, I. S.; MICHELI, G.; SARIAN, R. Clorexidina - os prós e os contras da sua utilização em Periodontia. Rev Assoc Paul Cir Dent, v. 43, n. 1, p. 20-23, jan./fev. 1989.

6. FROSTELL, G. In vitro effect of cetylpyridinium chloride (Biosept) on oral strains of Candida albicans. Dent Abstracts, v. 1, p. 238-239, Apr. 1956.

7. GAYOTTO, M. V.; SANTOS, M. A. A.; GREGORI, C. Bacteriemias transitórias por microrganismos anaeróbios, pós-remoção de fios de sutura. Rev Odontol Univ São Paulo, v. 1, n. 3, p. 52-62, jul./set. 1987.

8. GIGLIO, J. A.; ROWLAND, R. W.; DALTON, H. P.; LASKIN, D. M. Suture removal-induced bacteremia: a possible endocarditis risk. J Am Dent Assoc, v. 123, n. 8, p. 65-70, Aug. 1992.
9. KING, R. C.; CRAWFORD, J. J.; SMALL, E. W. Bacteremia following intraoral suture removal. Oral Surg Oral Med Oral Pathol, v. 65, n. 1, p. 23-28, Jan. 1988.

10. LIEDKE, E. D.; SANTOS, J. O. S.; CARVALHO, M. S. Fios de sutura e presença de placa microbiana. Rev Gaúcha Odontol, v. 23, n. 2, p. 105-06, abr./jun. 1975.

11. LILLY, G. E. Reaction of oral tissues to suture materials. Oral Surg Oral Med Oral Pathol, v. 26, n. 1, p. 128-133, July 1968.

12. LOWBURY, E. J. L.; LILLY, H. A. The effect of blood on disinfection of surgeons' hands. Br J Surg, v. 61, p. 19-23, 1974.

13. ROCHA BARROS, V. M. Anti-sepsia intrabucal précirúrgica. Avaliação da eficiência de três métodos e da frequiência de bacteriemia após exodontia. Ribeirão Preto, 1996. Tese (Livre-Docência) - Faculdade de Odontologia de Ribeirão Preto, Universidade de São Paulo.

14. SALOMÃO, J. I. S; ITO, I. Y.; PALAMIN, R. V. et al. Effect of antisepsis of the human alveolar surgical wound on bacterial growth on cotton suture. Rev Fac Farm Odont Rib Preto, v. 19, n. 1, p. 11-20, jan./jun. 1982.

15. SIMMONS, N. A.; CAWSON, R. A.; EYKYN, S. J. et al. Antibiotic prophylaxis of infective endocarditis: recommendations from the Endocarditis Working Party of the British Society for Antimicrobial Chemotherapy. Lancet, v. 335, p. 88-89, Jan. 1990.

16. YOUNG, S. E. J. A. Etiology and epidemiology of infective endocarditis in England and Wales. J Antimicrob Chemother, v. 20 (Suppl. A), p. 7-14, 1987.

Recebido para publicação em 13/03/2000

Enviado para reformulação em 27/09/2000

Aceito para publicação em 04/12/2000 